\title{
Fault Signal Propagation through the PMSM Motor Drive Systems
}

\author{
Jing Li \\ Member, IEEE \\ University of Nottingham, \\ Ningbo, China \\ 315100, Ningbo, China \\ Jing.Li@nottingham.edu.cn
}

\author{
Mark Sumner \\ Senior Member, IEEE \\ University of Nottingham \\ University Park \\ NG7 2RD, UK \\ Mark.Sumner@nottingham. \\ ac.uk
}

\author{
Jesus Arellano- \\ Padilla \\ Member, IEEE \\ University of Nottingham \\ University Park, NG7 2RD, \\ UK \\ jesus.arellano@nottingham. \\ ac.uk
}

\author{
He Zhang \\ Member, IEEE \\ University of Nottingham, \\ Ningbo, China \\ 315100, Ningbo, China \\ He.Zhang@nottingham.edu \\ .cn
}

\begin{abstract}
This paper describes how a mechanical disturbance on the shaft of a variable speed permanent magnet motor (PMSM) is propagated to the supply input side of the drive system, and therefore may be detected by monitoring specific frequency components in the rectifier input current. The propagation of the disturbance from the torque disturbance, to the motor current, then to the dc link current and finally to the rectifier input current is derived as a series of transfer functions so that both the frequency and the amplitude of the disturbance component in the rectifier input current can be predicted for a specific mechanical disturbance. The limitations to detect the mechanical fault by monitoring only the supply currents are also addressed. Simulation and experimental results are presented to demonstrate the accuracy of the quantitative analysis, and the potential for fault detection using the rectifier input currents.
\end{abstract}

Index Terms: Mechanical Faults, Motor Drive System, Fault Signal Propagation, PWM inverter, Fault Detection

\section{NOMENCLATURE}

$f_{r} \quad$ motor rotation frequency

$f_{f} \quad$ disturbance(fault) frequency

$f_{e} \quad$ motor excitation frequency

$f_{i} \quad$ rectifier input frequency

$T_{d} \quad$ mechanical fault applied on the motor

$T_{d f}, \varphi_{f}$ the amplitude and phase of the torque disturbance caused by faults

$i_{q f}$ disturbance current in the torque producing current

$I_{q f}, \Phi_{i}$ amplitude and phase of $i_{q f}$

$w_{r f}, \Phi_{w}$ amplitude and phase of the speed disturbance caused by the torque disturbance

$i_{\text {idcf }} \quad$ Inverter dc side disturbance

$I_{i D C} \mathrm{dc}$ component of the inverter dc side disturbance current

$I_{r d c f} \quad$ rectifier de side disturbance current

$I_{r D C} \quad$ dc component of the rectifier de side current

$I_{\text {raf }}$ rectifier ac side disturbance current

$u_{i d c} \quad$ Inverter de side voltage

$U_{r d c} \quad$ rectifier de side voltage

$S_{a}, S_{b}, S_{c} \quad$ switching functions for phase a,b and c

$e_{a}, e_{b}, e_{c}$ three phase supply voltage of the diode bridge

$i_{r a}, i_{r b}, i_{r_{c}}$ rectifier input a,b,c phase current

$J, B \quad$ motor inertia and friction
$L_{d}, L_{q} \quad$ motor d,q axix inductance

$\mathrm{P} \quad$ motor pole pair number

$R_{S} \quad$ motor stator resistance

Kt motor torque constant

$u \quad$ rectifier overlap angle

$\mathrm{L}_{\mathrm{r}}, \mathrm{R}_{\mathrm{r}} \quad$ rectifier equivalent inductance and resistance

$M \quad$ modulation index of PWM inverter

\section{INTRODUCTION}

Condition monitoring can improve the reliability of motor drive systems, and with sufficient resolution and knowledge, can be used to detect faults before they disrupt the drive operation. Many diagnostics methods have been investigated and applied, such as monitoring of vibration [1,2], the flux measurement [3], and the thermal monitoring [4]. These techniques tend to be employed for larger industrial drives and generators. Permanent magnet synchronous motors (PMSM) are now being generally employed for applications in "more electric aircraft" [5] and also in applications such as power steering in automobiles due to their high power density and high efficiency. For these applications it is usually not feasible to use the additional complexity of vibration or thermal measurements [6] due to cost, space or reliability concerns.

Motor current signature analysis(MCSA) [7] is the most widely spread approach for condition monitoring, especially for mechanical faults [8]. MCSA requires measurement and processing of the stator currents to identify any abnormality in the machines by detecting changes in the harmonic content. However, measurement of the machine currents may be impractical in some cases such as those where the power converter and the machine are integrated in a single unit or when the access to the machine and the power converter is impractical due to their location $[9,10]$. The use of integrated drives is being encouraged in aerospace and automotive applications; if there is a fault it is easier to replace the full unit without affecting other systems. Integrated drives are usually considered as a 'black box' purchased from a third party so the access to internal signals is not always possible. It also may be preferable to monitor the drive's condition 'externally', to provide a fault detection mechanism which is 
independent of the drive itself. This may be achieved by monitoring the drive's supply currents. In [9], the author proposed an new approach to detect the turn-to-turn short circuit fault of the generators by using only the dc current information because of the difficulty to access the built-in rectifier ac current or the voltage of the generator.

This paper provides a theoretical analysis of the propagation path that a mechanical fault follows through the drive (in terms of both frequency and amplitude) from the torque disturbance to the rectifier input current which is the supply current of the whole motor drive system. This quantitative theoretical analysis provides the base and proposes limitation of the condition monitoring approach based on using only the ac supply current information. This includes the effect of the PMSM (through its torque producing current $i_{q}$ and the speed ripple), the PWM inverter, the dc link LC filter and the uncontrolled rectifier. The analysis predicts not only the location of the sideband harmonics in the input rectifier current due to the torque disturbances seen by the machine, but also their magnitudes. This is important since this analysis could be used to estimate the impact of mechanical faults on the ac grid or to develop auto tuning monitoring schemes in those systems operating under constantly changing conditions. This paper is focused only on the mechanical faults signature propagation.

The presentation of this paper is as follows: Section III gives a short explanation of expected torque disturbances due to several typical mechanical faults in a drive system. Section IV explains the propagation effect of the fault signatures and presents the analytical scheme to predict the frequency and magnitude of the fault signatures in the rectifier input current. In section $\mathrm{V}$, the minimum torque disturbance caused by the mechanical faults which can be detected by the drive supply current monitoring is analyzed based on the analysis given in section IV. The fault signal transfer function is evaluated by simulation in Section VI, while experimental results are considered in Section VII. Finally, discussion and conclusions are included in Section VIII and IX respectively.

\section{Mechanical Faults IN Servo Drive Systems}

Both mechanical fault and electrical faults generate torque disturbances [11]. In this paper, only the mechanical faults are studied. Common mechanical faults in variable speed drives are bearing faults, eccentricity related faults and gearbox faults. Each fault type has a set of characteristic torque disturbance frequencies associated with it. To be able to diagnose a specific mechanical fault by detecting a disturbance frequency in the supply current, the machine's speed and the characteristic frequencies of specific mechanical faults need to be known.

\section{A. Bearing Faults}

Bearing faults including outer race defect, inner race defect, ball defect and cage defect will cause an increment in vibration and therefore a torque disturbance related to the fault. The vibration frequency will be determined by the motor speed, the bearing fault type and the bearing geometry. Typical frequencies are given in[12-14] .

\section{B. Eccentricity Related Faults}

The term "Eccentricity" is usually employed when the air gap in the machine is not uniform. This results when the stator bore is not properly manufactured or there is an incorrect mounting of the rotor and can be classified into two categories: static or dynamic [3]. For static eccentricity, the minimum air gap is fixed at the same geometric position. In the case of static eccentricity, the non-uniformity of the air gap and therefore flux is time independent [15]. Severe static eccentricity can give rise to unbalanced magnetic pull, and therefore causes shaft flexing and dynamic eccentricity [2]. For the case of dynamic eccentricity, the centre of the rotor is not exactly the centre of the stator core and the minimum air gap position will rotate with the rotor. If both static and dynamic eccentricities exist together, the torque disturbance components $\left(f_{\text {ecc }}\right)$ which are integer times of the rotational frequency may be observed, which are given by [6]:

$$
f_{e c c}=n \cdot f_{r}
$$

where $f_{r}$ is the motor rotational frequency and $n=1,2,3 \ldots$

\section{Gearbox Faults}

When defective gears are present, a vibration will be clearly observed and the spectrum of the vibration will indicate the gear fault. For a single defect on a single tooth such as a cracked, broken, or missing tooth, a shock pulse will be induced each time this defect tooth meshes. Therefore, the vibrations will be $n \cdot f_{r}$ and also will show up as the sideband of the mesh frequencies: $f_{m} \pm n \cdot f_{r}$ where $n=1,2,3, \ldots$ and $f_{m}$ is the gear mesh frequency $\left(f_{m}=N \cdot f_{r}\right.$, where $N$ is teeth number of the gear [6]). If there are two defective teeth, two shock pulses will be created in each revolution and the vibration will be $2 n \cdot f_{r}$ [16].

Most of the faults described in this section create a torque disturbance whose frequency can be estimated if the characteristics of the mechanical system and the shaft speed are known. The work described in this paper considers the faults which appear as a torque disturbance on the shaft, and does not consider additional flux coupling effects due to nonuniform airgap. The approach will therefore concentrate on faults such as gear faults, faults on bearings external to the motor, and faults which develop in the load application itself.

\section{Signal Propagation through the Drive System}

This section analyses how a torque disturbance applied to the shaft of the machine propagates through the motor drive and appears as frequency components in the rectifier input currents. The typical structure of a three phase 
motor drive system is shown in Fig.1. To analyze the fault propagation, the motor drive system is split into three parts: the machine (PMSM), the PWM inverter and the three-phase 6-pulse uncontrolled rectifier linked to the inverter through a dc link LC filter.

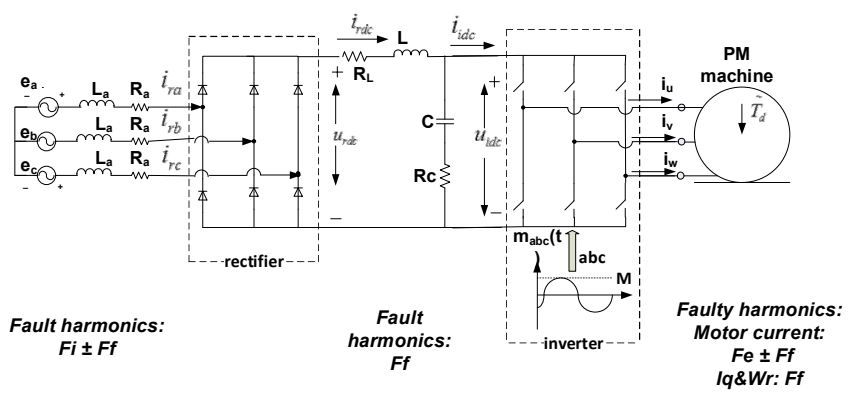

Fig. 1 PMSM motor drive system[20]

\section{A. Fault Signal Propagating through the Machine:}

A PMSM is usually controlled using a method such as vector control [17]. The vector control method decouples the stator current into independent field and torque producing components through coordinate transformations and then controls the electrical torque of the machine directly through the fast current control [18]. A PMSM drive controlled by the vector control method together with its voltage decoupling compensation is shown in the Fig.2. while the simplified control schematic of the servo drive system is shown in Fig.3.

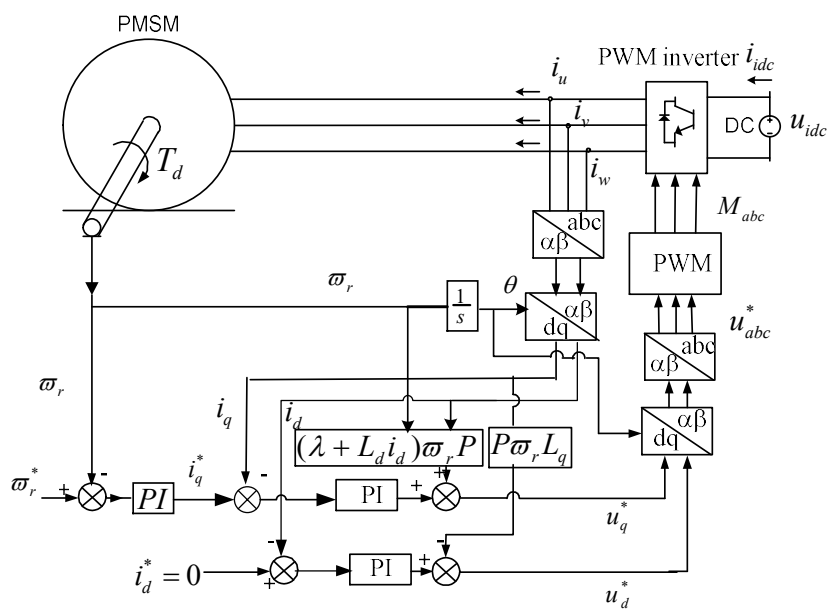

Fig. 2 Vector Control for a PMSM

A mechanical fault appearing at the shaft of the motor running in steady state will cause torque disturbance whose frequency $f_{f}$ is determined by the fault type as described in the previous section. This torque disturbance will create a fluctuation in the speed of the machine at the same frequency. The outer loop speed controller will therefore attempt to reduce this fluctuation and a component will appear at the disturbance frequency on both the torque producing ( $q$-axis) current reference and the actual $q$-axis current $i_{q}$. This disturbance in $i_{q}$ will be observed as two sideband components: $\left|f_{e} \pm f_{f}\right|$ around the motor excitation frequency $f_{e}$ in the stator currents of the machine [19].

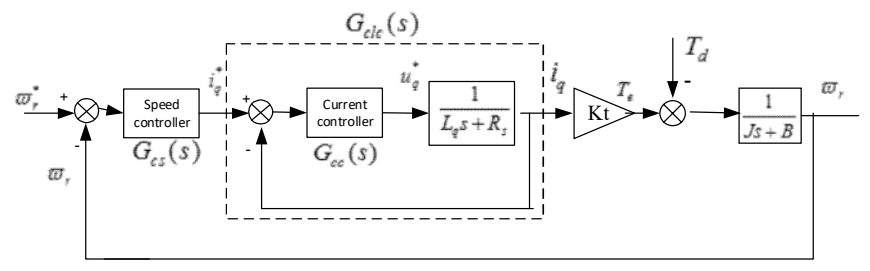

Fig. 3 Close loop control scheme for the servo drive

From Fig.3, the disturbance current component $\left(i_{q f}\right)$ can be derived from the transfer function relating the torque disturbance $T_{d}$ to the $q$-axis current $i_{q}$. The transfer function for this system will be referred as $G_{I_{q} 2 T_{d}}(s)$ and is given by (2)[20].

$$
G_{I_{q} 2 T_{d}}(s)=\frac{I_{q}(s)}{T_{d}(s)}=\frac{-\frac{1}{J_{S}+B} \cdot G_{c s}(s) \cdot G_{c l c}(s)}{1+G_{c s}(s) G_{c l c}(s) \frac{1}{J_{s}+B} K_{t}}
$$

where $G_{c s}(s)$ is the speed controller; $\mathrm{Kt}$ is the machine's torque constant, $\mathrm{J}$ is the inertia and $\mathrm{B}$ is the frictional coefficient. $G_{c l c}(s)$ is the transfer function of the closed loop current control which is given by (3) [20]:

$$
G_{c l c}(s)=\frac{I_{q}(s)}{I_{q}^{*}(s)}=\left[G_{c c}(s) \frac{1}{L_{q} s+R_{s}}\right] /\left[1+G_{c c}(s) \frac{1}{L_{q} s+R_{s}}\right]
$$

where $G_{c c}(s)$ is the current controller, $L q$ is the q-axis inductance, and $R s$ is the stator resistance. The amplitude and phase of $i_{q f}$ can be derived as:

$I_{q f}=\left.\left|G_{I_{q} 2 T_{d}}(s)\right|\right|_{s=j \sigma_{f}} \cdot T_{d f}, \quad \phi_{i}=\left.\angle G_{I_{q} 2 T_{d}}(s)\right|_{s=j \sigma_{f}}+\varphi_{f}$

where $T_{d f}$ and $\varphi_{f}$ are the amplitude and phase of the torque disturbance at the disturbance frequency $f_{f}$ caused by the specific mechanical fault. $\varpi_{f}=2 \pi \cdot f_{f}$. In a similar way, the speed fluctuation caused by the fault can be calculated by using expression (5) which relates the motor speed to the torque disturbance: [20]

$G_{\varpi_{r} 2 T_{d}}(s)=\frac{\varpi_{r}(s)}{T_{d}(s)}=1 /\left[(J s+B)\left(1+G_{c s}(s) G_{c l c}(s) \frac{1}{J s+B} K_{t}\right)\right]$

The speed change in terms of amplitude and phase response $\left(\varpi_{r f}\right.$ and $\left.\phi_{\sigma}\right)$ due to a torque disturbance can be expressed as: [20]

$\varpi_{r f}=\left.\left|G_{\varpi 2 T_{d}}(s)\right|\right|_{s=j \sigma_{f}} \cdot T_{d f}, \quad \phi_{\varpi}=\left.\angle G_{\varpi 2 T_{d}}(s)\right|_{s=j \sigma_{f}}+\varphi_{f}$ 
It can be seen that for a given drive and load, the bandwidth of the speed controller has a significant effect on the propagation of the fault through the drive system. High performance "servo drives" have relatively high speed controller bandwidths, and will therefore create a higher amplitude disturbance in $i_{q}$ than lower bandwidth speed controllers.[21]

\section{B. Fault Signal Propagating through the PWM Inverter}

Considering the sub-system including the PWM inverter and the PMSM, which is depicted in Fig.2, the disturbance components on $i_{q}$ and the motor speed will be propagated to the inverter dc side current at the same frequency $f_{f}$. Assuming no conduction loss in the inverter, the instantaneous active power on the inverter $\mathrm{dc}$ and ac side should always be equal [i.e., $P_{a c}(t)=P_{d c}(t)$ ] [22], which can be calculated as:

$$
\begin{aligned}
& P_{d c}(t)=U_{d c} \cdot i_{d c}(t) \\
& P_{a c}(t)=\frac{3}{2}\left[u_{d}(t) \cdot i_{d}(t)+u_{q}(t) \cdot i_{q}(t)\right]
\end{aligned}
$$

where $U_{d c}$ is the mean value of the inverter dc side voltage; the $3 / 2$ term results from the use of the peak convention for the transformations [23]. $u_{d}(t)$ and $u_{q}(t)$ are control variables and can be deduced from the $D Q$ model of the machine given by (9) and (10). [23]

$$
\begin{aligned}
& u_{d}(t)=L_{d} \cdot \frac{d}{d t} i_{d}(t)+R_{s} i_{d}(t)-P \cdot \varpi_{r}(t) L_{q} \cdot i_{q}(t) \\
& u_{q}(t)=L_{q} \cdot \frac{d}{d t} i_{q}(t)+R_{s} i_{q}(t)+P \cdot \varpi_{r}(t) \cdot\left[L_{d} \cdot i_{d}(t)+\lambda\right]
\end{aligned}
$$

where $\lambda$ is the flux generated by the rotor permanent magnets, and $P$ is the number of pole pairs. If an ideal vector controller is assumed, then $i_{d}$ is controlled to be zero [23]. If eccentricity effects were to be considered, they would contribute a fault related component to the flux. For this work, airgap related faults have been ignored. Combining (7), (8), (9) and (10), the fault current $\left(i_{\text {idcf }}\right)$ at $f_{f}$ on the inverter dc side can be calculated with a very high accuracy if the system parameters(motor parameters, speed and current controllers) are well known, by using the following expression: [20]

$$
i_{i d c f}(t)=\frac{3}{2 U_{d c}} \sqrt{a^{2}+b^{2}+2 a b \cos \left(\varphi_{1}+\varphi_{i}-\varphi_{\varpi}\right)} \sin \left(\varpi_{f} t+\varphi_{2}\right)
$$

where $\varphi_{i,}, \varphi_{\sigma}$ are defined in (4) and (6) respectively, and $I q$ is the de component of $i q$.

$$
\begin{aligned}
& a=I_{q f} \sqrt{\left(2 R_{s} I_{q}+P \cdot \varpi_{r}^{*} \cdot \lambda\right)^{2}+\left(L_{q} I_{q} \varpi_{f}\right)^{2}} \\
& b=I_{q} \lambda \cdot P \cdot \varpi_{r f},
\end{aligned}
$$

$\varphi_{1}=\tan ^{-1}\left(L_{q} I_{q} \varpi_{f} /\left(2 R_{s} I_{q}+P \cdot \varpi_{r}^{*} \cdot \lambda\right)\right)$,

$\varphi_{2}=\tan ^{-1}\left(\frac{a \cdot \sin \left(\varphi_{i}+\varphi_{1}\right)+b \cdot \sin \left(\varphi_{\varpi}\right)}{a \cdot \cos \left(\varphi_{i}+\varphi_{1}\right)+b \cdot \cos \left(\varphi_{\varpi}\right)}\right)$

It is assumed that the ripple in the motor speed is kept very small by the speed controller, and therefore only appears as very small components of the PWM modulation index $M$. These are reasonable assumptions to make, especially if the motor is operating at medium or high speed and the fundamental component of the modulation index is reasonably large. According to these assumptions, the disturbance component in (11) can be simplified as [20]: $I_{d c f}=3 / 4 I_{q f} M \cos (r)$

where $M$ is the fundamental component of the modulation index, $\mathrm{r}$ is the phase difference between the motor phase voltage and the current, and $\cos (r)$ is the power factor of the load. Since a PMSM machine usually operates at a very high power factor (i.e. close to unity), component $\cos (r)$ can also be neglected to simplify the analysis.

\section{Fault Signal Propagating through the Rectifier Bridge}

A three-phase diode bridge rectifier with an $L C$ filter and a disturbance current source on the dc side is shown in Fig 4.

The supply voltages $e_{a}, e_{b}, e_{c}$ are defined as:

$e_{a}=E \sin \left(\varpi_{i} t\right), e_{b}=E \sin \left(\varpi_{i} t-\frac{2}{3} \pi\right), e_{c}=E \sin \left(\varpi_{i} t+\frac{2}{3} \pi\right)($

where $\varpi_{i}=2 \pi f_{i}$ and $f_{i}$ is the rectifier input frequency. The rectifier load current $i_{\text {load }}$ consists of three components [25]: the dc load current $I_{I D C}$, harmonics related to the supply, and a disturbance current $i_{f}=I_{f} \sin \left(\varpi_{f} t\right)$ transmitted from the inverter de side at frequency $f_{f}$ and is given by:

$i_{\text {load }}=I_{I D C}+\sum_{h=6,12, \ldots}^{\infty} i_{l h}+i_{f}$

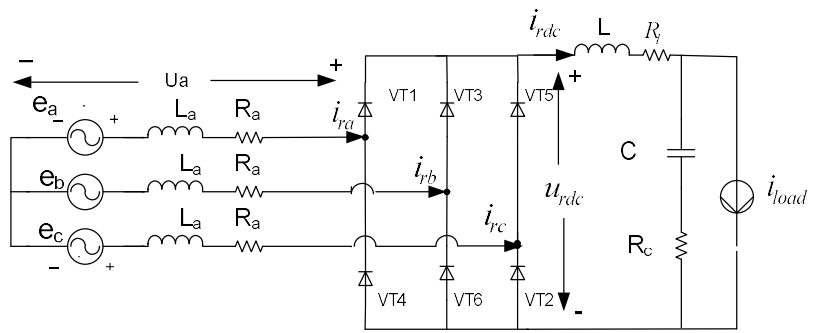

Fig. 4 Three-phase diode bridge rectifier with a LC filter[20] 


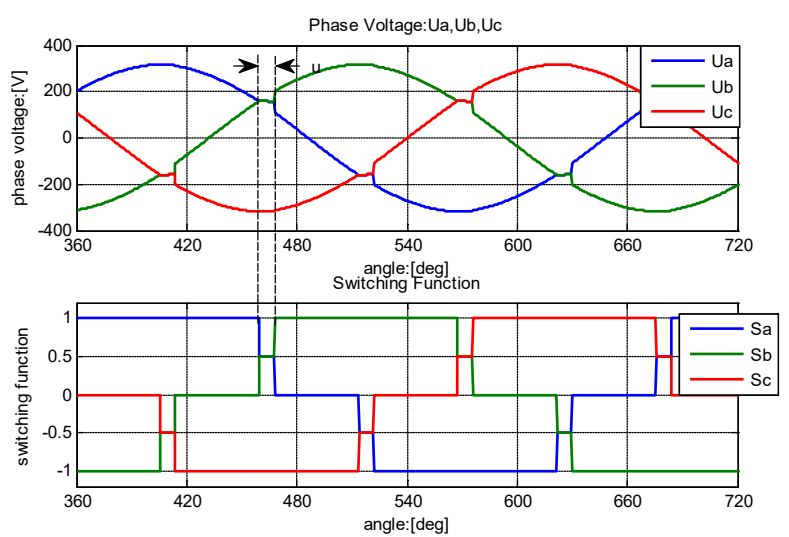

Fig. 5 Switching function for a six-pulse uncontrolled rectifier[20]

To analyze the operation of the uncontrolled rectifier, the switching function is applied [24]. With the switching function $S_{a}, S_{b}$ and $S_{c}$ per phase, the input and output voltage and current of a six-pulse uncontrolled rectifier can be related using the following equations: [24]

$u_{r d c}=S_{a} u_{a}+S_{b} u_{b}+S_{c} u_{c}$

$i_{r a}=i_{r d c} \cdot S_{a}, i_{r b}=i_{r d c} \cdot S_{b}, i_{r c}=i_{r d c} \cdot S_{c}$

The switching function for each phase is decided by the operation of the diodes in each phase as shown in Fig.5. The switching function for the specific phase should be 1 or -1 in the non-overlap conducting period, be 0.5 or -0.5 when the diode is in overlap period, i.e. commutating to another phase, and be zero when the diode is not conducting [24].

Treating the bridge diodes as ideal switches, with a balanced three-phase ac power supply and the rectifier operating in the continuous conduction mode [24], the switching function $\left(S_{a}\right)$ for phase $a$ can be derived using a Fourier Series :

$S_{a}=\sum_{k=1,5,7, \ldots}^{\infty} \frac{\sqrt{3}}{\pi} \cdot \frac{(-1)^{l+1}}{k}\{\sin (k u) \cos (k \theta)-[1+\cos (k u)] \sin (k \theta)\}$

where $k=6 l \pm 1,(1=0,1,2, \ldots, \mathrm{k}>0)$ and $u$ is the overlap angle, which is given by: [24]

$$
u=\cos ^{-1}\left(1-2 \varpi_{i} \cdot L_{a} \cdot I_{l D C} /(\sqrt{3} E)\right)
$$

For a balanced three-phase system, the switching functions $\left(S_{b}, S_{c}\right)$ for phases $b$ and $c$ can be easily derived with $\left(-\frac{2}{3} \pi\right)$ and $\left(\frac{2}{3} \pi\right)$ phase shifts from $S_{a}$ respectively [24]. Assuming that the disturbance current on the rectifier dc side caused by the fault is $i_{r d c f}=I_{r d c f} \sin \left(\varpi_{f}+\alpha_{r}\right)$, the disturbance current on the rectifier ac side $\left(i_{\text {raf }}\right)$ can be derived from $i_{r d c f}$ using (16) as: $i_{r a f}=i_{r d c f} S_{a}$. The disturbance component of the output voltage of the diode bridge $u_{r d c f}$ can be deduced using(15):

$$
\begin{aligned}
& u_{r d c f}=S_{a}\left[L_{a} \frac{d\left(i_{r d c f} S_{a}\right)}{d t}+R_{a} S_{a} i_{r d c f}\right]+S_{b}\left[L_{a} \frac{d\left(i_{r d c f} S_{b}\right)}{d t}+R_{a} S_{b} i_{r d c f}\right] \\
& +S_{c}\left[L_{a} \frac{d\left(i_{r d c f} S_{c}\right)}{d t}+R_{a} S_{c} i_{r d c f}\right]
\end{aligned}
$$

To simplify the calculation, only the first order component of the switching function is considered. This simplification will produce an error when $L_{a}$ is significant when compared to $L$ therefore this simplification is only suitable for applications where the filtering inductor is placed on the dc side rather than the ac side of the rectifier. This is usually the case for systems where the rectifier harmonic content is considered as part of the drive design such as drives for more electric aircrafts, rather than fitted retrospectively. The component $u_{r d c f}$ can therefore be simplified to:

$$
\begin{aligned}
& u_{r d c f 1}=\frac{9}{\pi^{2}} L_{a}[1+\cos (u)] I_{r d c f} \varpi_{f} \sin \left(\varpi_{f} t+\alpha_{r}+\frac{\pi}{2}\right) \\
& +\frac{9}{\pi^{2}} R_{a}[1+\cos (u)] I_{r d c f} \sin \left(\varpi_{f} t+\alpha_{r}\right)
\end{aligned}
$$

By only considering the disturbance frequency $f_{f}$, according to (20), the uncontrolled diode bridge, the dc link filter and the load can be represented by the equivalent circuit shown in Fig.6, where $R_{r}$ and $L_{r}$ are the equivalent resistance and inductance transferred from the rectifier ac side to the dc side using the switching function of the uncontrolled diode bridge. [20]

$$
L_{r}=\frac{9}{\pi^{2}} L_{a}(1+\cos (u)), R_{r}=\frac{9}{\pi^{2}} R_{a}(1+\cos (u))
$$

With this equivalent circuit and considering only the first order of the switching function, the magnitude of the disturbance current $\left(I_{r d c f}\right)$ on the rectifier dc side can be derived from the current disturbance component $i_{f}$ in the load current as: [20]

$$
I_{r d c f}=I_{f} \cdot\left|\frac{\frac{1}{j \varpi_{f} C}+R_{c}}{\frac{1}{j \varpi_{f} C}+R_{c}+j \varpi_{f}\left(L+L_{r}\right)+R_{l}+R_{r}}\right|
$$

The disturbance current on the rectifier dc side $\left(I_{r d c f}\right)$ will be transferred to the ac side as two sideband components in $\left(i_{\text {raf }}\right)$ i.e., $\left|f_{i} \pm f_{f}\right|$ around the rectifier supply frequency $f_{i}$ , whose amplitude can be derived using the first order of the switching functions: [20]

$I_{r a f}=\frac{\sqrt{6}}{\pi} \sqrt{1+\cos (u)} I_{r d c f}$

Note that if the drive were fed from a dc rather than an ac supply, such as drives found in automotive systems, or those in aircrafts with dc supplies, then the transfer function 
associated with the supply side would simply consider the dc link filter.

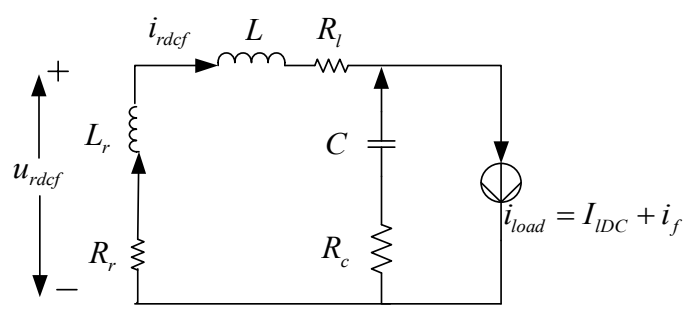

Fig. 6 Equivalent circuit at the fault frequency in the rectifier[20]

\section{Signal Propagation through the Full Servo Drive}

The system considered in this paper is the integrated system shown in Fig. 1, in which the rectifier system shown in Fig. 4 and the inverter driven PMSM motor system given in Fig. 2 are connected with the dc link LC filter. Therefore, the disturbance current in the PMSM q axis $\left(i_{q f}\right)$ and motor speed ripple $\left(\varpi_{r f}\right)$ caused by the torque disturbance will propagate through the PMSM, PWM inverter, the dc link filter and the rectifier and finally arrives at the rectifier ac side as a disturbance current component $\left(i_{r a}\right) . i_{r a}$ can be calculated from the disturbance current component in dc link current $\left(i_{i d c f}\right)$. If only the disturbance(fault) frequency is considered, the integrated system shown in Fig.1 can be depicted as the equivalent circuit shown in Fig.7, in which the rectifier ac side impedance is transferred into the dc side using (20) and (21) based on the switching function. The machine is modelled in the $d q$ frame introduced in (9) and (10), while the PWM inverter can be represented as a transformer [25], which is depicted in Fig.7[26].

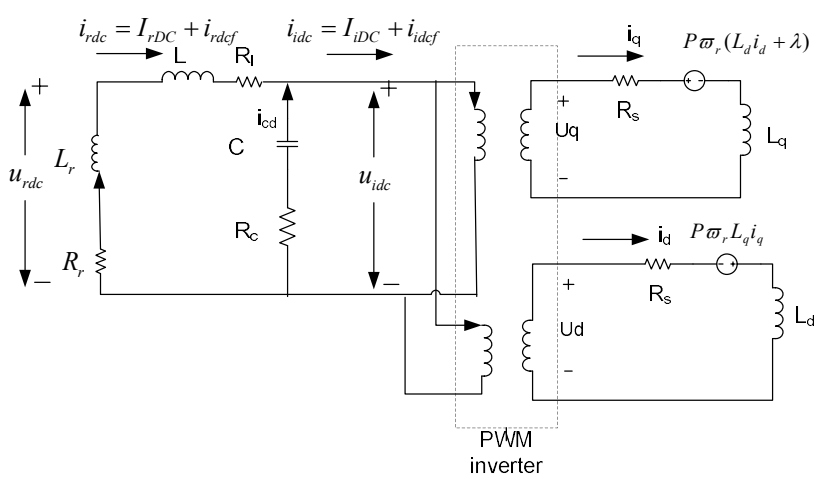

Fig.7 Equivalent circuit for the integrated system at the disturbance frequency[26]

This configuration is different from the system given in Fig.2, as the inverter dc side voltage is no longer considered to be an ideal dc voltage, and the disturbance component has been included. As only the disturbance signals are of concern in this paper, all the system related harmonic components are ignored. The inverter dc side current and voltage can be assumed to be:

$i_{i d c}=I_{i D C}+i_{i d c f}=I_{i D C}+I_{i d c f} \sin \left(\omega_{f} t+\varphi_{i f}\right)$ $u_{i d c}=U_{i D C}+u_{i d c f}=U_{i D C}+\sin \left(\omega_{f} t+\varphi_{u f}\right)$

where $I_{i D C}$ and $U_{i D C}$ are dc components.

Using (20), the inverter dc side instantaneous power can be expressed as:

$p_{i d c}=u_{i d c} \cdot i_{i d c}=\left[U_{i d c D C}-i_{i d c f} \cdot Z_{r}\left(j \varpi_{f}\right)\right] \cdot\left[I_{i d c D C}+i_{i d c f}\right]$

where: $Z_{r}\left(\omega_{f}\right)=\frac{\left(\frac{1}{j \sigma_{f} C}+R_{c}\right) \cdot\left[j \varpi_{f}\left(L+L_{r}\right)+R_{l}+R_{r}\right]}{\left(\frac{1}{j \sigma_{f} C}+R_{c}\right)+j \varpi_{f}\left(L+L_{r}\right)+R_{l}+R_{r}}$

As the instantaneous power on the inverter dc and the ac side should always be identical, $p_{i d c}=p_{i a c} \quad$ [22]. Combining (8) with (25), the disturbance current in the inverter dc side ( $\left.i_{i d c f}\right)$ can be derived as:

$I_{i d c f}=\frac{3}{2 U_{i d c}} \sqrt{a^{2}+b^{2}+2 a b \cos \left(\varphi_{1}+\varphi_{i}-\varphi_{\varpi}\right)} \frac{1}{1-\frac{z_{r}\left(j \varpi_{f}\right)}{\frac{U_{i d c D C}}{I_{i d c D C}}}}$

where $\varphi_{i,}, \varphi_{\sigma}$ are defined in (4) and (6), a, b and $\varphi_{1}$ are given in (11 a-c) . According to the equivalent circuit in Fig.7 and by considering (22) and (23), the rectifier input side disturbance current $\left(I_{r a f}\right)$ can be calculated from the torque disturbance caused by the fault condition by using the system mechanical and electrical parameters: [26]

$I_{\text {raf }}=$

$\frac{3 \sqrt{6}}{4 \pi U_{i d c D C}} \sqrt{[1+\cos (u)] \cdot\left[a^{2}+b^{2}+2 a b \cos \left(\varphi_{1}+\varphi_{i}-\varphi_{\varpi}\right)\right]}$

$\left|\left(\frac{1}{j \varpi_{f} C}+R_{c}\right) /\left\{\left[\frac{1}{j \varpi_{f} C}+R_{c}+j \varpi_{f}\left(L+L_{r}\right)+R_{l}+R_{r}\right] \cdot\left[1-\frac{z_{r}\left(j \varpi_{f}\right)}{\frac{U_{i d d D C}}{I_{i d c D C}}}\right]\right\}\right|$

Expression (27) defines how the disturbance torque is propagated through the integrated system to appear as a disturbance related component of the rectifier input current and can be used to estimate the magnitude of this component.

\section{LIMITATION OF CONDITION MONITORING METHOD BY MONITORING ONLY SUPPLY CURRENTS}

The most important objectives of theoretically deriving the fault signal transformation through the drive system is to understand the limitations of this diagnosis method by which only the supply currents are monitored when applied to a specific drive system, i.e. to understand the minimum torque disturbance caused by a mechanical fault which can be detected by this method using a specified experimental rig. Considering the practical applications, certain constraints for the measurement systems and the control strategy are not ignorable. All these measurement constrains, controller 
bandwidths, the fault frequency and system mechanical parameters (inertia and friction) will determine this minimum detectable torque disturbance. The most important factors determining this limit are the resolution of the speed/position measurement and the resolution/sensitivity of the analogue to digital converters (ADCs) used to measure the input current [26].

For the experimental system used in this research, the rotor position is sampled at $200 \mathrm{~Hz}$ for the speed controller. Therefore the maximum detectable disturbance frequency for the speed controller used in this work is the Nyquist frequency $100 \mathrm{~Hz}$. In this experimental rig, a 4096 pulse per revolution quadrature optical encoder is used to measure the rotor position to provide vector orientation and to obtain the rotor speed. The encoder resolution therefore is $\theta_{\text {res }}=2 \pi /(4 \times 4096)[\mathrm{rad}]$. As the speed loop sampling frequency is $200 \mathrm{~Hz}$, the speed resolution can be derived as: $\varpi_{r_{-} \text {res }}=\theta_{\text {res }} \cdot f_{s}=0.0767[\mathrm{rad} / \mathrm{sec}]$. For aerospace applications, to achieve the high performance and the accurate control, normally, analogue resolvers will be used rather than encoders. Therefore, the analogue to digital converter (ADC) resolution will affect the detection limitations. Since the ADC resolution is much better than the encoder resolution, the speed loop sampling frequency can be increased significantly to achieve the certain speed measurement resolution. [26]

To guarantee that the speed oscillation can be detected by the encoder, the peak to peak amplitude of the speed ripple created by the mechanical fault need to be bigger than this speed resolution $\varpi_{r_{-} r e s}$. With the transfer function $G_{\varpi 2 T_{d}}(s)$ from the motor speed to the torque disturbance given in (5), the minimum torque disturbance can be calculated with:[26]:

$$
\begin{aligned}
& T_{d_{-} \text {detectable_ } \sigma_{r}}=\left|\frac{0.5 \varpi_{r_{-} r e s}}{G_{\varpi 2 T_{d}}(s)}\right|_{s=j \sigma_{f}} \\
& \left.=0.03835 \cdot \mid J_{S}+B+G_{c s}(s) G_{c l c}(s) K_{t}\right]\left.\right|_{s=j \sigma_{f}}
\end{aligned}
$$

where $G_{c l c}(s)$ is given in (3), and $G_{c s}(s)$ is the speed loop controller.

By substituting the motor parameters and the speed and current controllers used in this work, the minimum detectable torque disturbance (as constrained by the encoder resolution) plotted as a function of the fault frequency is shown in Fig. 8 (red curve). Generally this minimum measureable torque disturbance increases with increasing fault frequency due to the bandwidth of the speed loop.

The other major factor affecting this minimum detectable torque disturbance is the resolution/sensitivity of the analogue to digital converter for the current transducers implemented in the systems. There are two sets of current transducers applied in the whole system. One set is sensing the PMSM motor currents to provide feed-back for the current control and another set is used to detect the rectifier input current to diagnose fault conditions. The ripple in supply currents produced by the fault conditions has to be detectable and also a good accuracy needs to be provided to guarantee the accuracy of the current control and diagnosing the faulty condition. For this research, 16 bit ADCs were implemented. The measurement range of the current transducer implemented in this research is 20A. Ignoring the first bit for the sign, the ADC resolution for the rectifier input current is: $I_{r e s}=\frac{I_{\max }}{2^{15}}=0.6 \mathrm{~mA}$. However, in practice, the current transducer operates in a noisy environment. From the calibration, the minimum change in the current that can be sensed with this current transducer applied in the experimental test is about $2 \mathrm{~mA}$. Since $2 \mathrm{~mA}$ is much bigger than $0.6 \mathrm{~mA}, 2 \mathrm{~mA}$ will be considered when calculating the detection limitation. The disturbance component in the rectifier input current caused by the mechanical faults need to be bigger than the minimum detectable threshold $(2 \mathrm{~mA})$ of the current transducer to indicate the fault condition. Using (27), the minimum torque disturbance detectable for the current transducer/ADC used can be calculated as a function of disturbance frequency as shown in Fig. 8 (blue curve). It is interesting to note the effect of the dc link LC circuit - its resonant frequency is around $68 \mathrm{~Hz}$ - and this resonant effect may be used to improve detection resolution.

The other set of the current transducers applied in this PMSM motor drive system are the ones measuring motor stator currents. The $i_{q}$ current is transformed from measured three-phase PMSM stator currents through the DQ transformation and 2/3 transformation.[27]

$$
\left[\begin{array}{c}
i_{a}(t) \\
i_{b}(t) \\
i_{c}(t)
\end{array}\right]=\left[\begin{array}{cc}
\cos (\varpi t) & -\sin (\varpi t) \\
\cos \left(\varpi t-\frac{2}{3} \pi\right) & -\sin \left(\varpi t-\frac{2}{3} \pi\right) \\
\cos \left(\varpi t+\frac{2}{3} \pi\right) & -\sin \left(\varpi t+\frac{2}{3} \pi\right)
\end{array}\right]\left[\begin{array}{c}
i_{d}(t) \\
i_{q}(t)
\end{array}\right]
$$

$\left[\begin{array}{l}i_{d}(t) \\ i_{b}(t) \\ i_{c}(t)\end{array}\right]=$

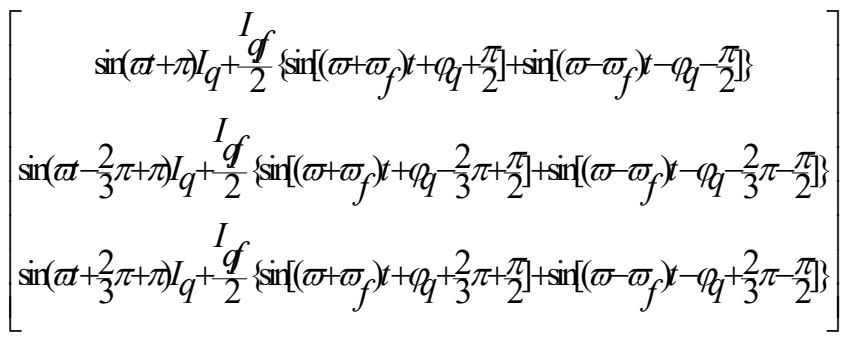

$$
\begin{aligned}
& \text { According to } \quad(29)[27] \quad \text { and the } \\
& i_{d}(t)=0, i_{q}(t)=I_{q}+I_{q f} \sin \left(\varpi_{f} t+\varphi_{q}\right) \text {, the stator currents can }
\end{aligned}
$$


be derived as (30). From (30), it can be seen that $i_{q}$ disturbance component with the frequency $f_{f}$ generates two sideband disturbance components: $\left|f_{e} \pm f_{f}\right|$ in the stator currents with the attenuation as 0.5 . When a torque disturbance occurs in the motor system due to a fault condition, if the minimum detectable disturbance current in the stator currents is $2 \mathrm{~mA}$, the minimum detectable $i_{q}$ current ripple at the disturbance frequency should be $4 \mathrm{~mA}$. Similar to the encoder resolution, using the transfer function from the $i_{q}$ current to the torque disturbance presented in (4), the minimum torque disturbance to make the disturbance current measurable by the current loop can be derived by (31) which is also illustrated in Fig 8(green curve):

$$
\begin{aligned}
& T_{d_{-} \text {detectable_I } I_{q}}=\left|\frac{I_{q_{-} \text {measure }}}{G_{I_{q} 2 T_{d}}(s)}\right|_{s=j \sigma_{f}}\left|\frac{J S+B+G_{c S}(s) G_{c l c}(s) K_{t}}{G_{c s}(s) G_{c l c}(s)}\right|_{s=j \sigma_{f}} \\
& =0.002 \cdot \mid \frac{J_{s}}{}
\end{aligned}
$$

where $G_{c l c}(s)$ is the closed current loop transfer function and $G_{c s}(s)$ is the speed loop controller.

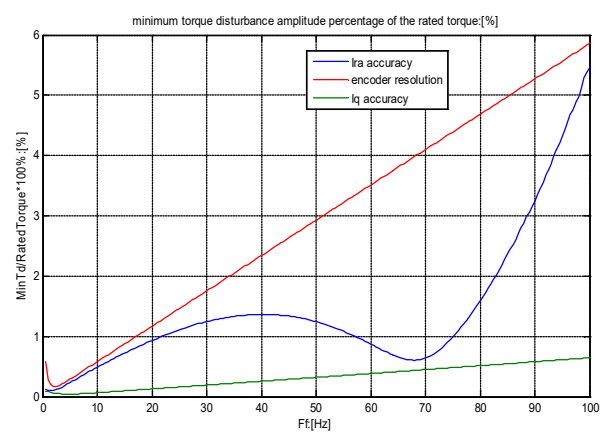

Fig. 8 Comparison of the minimum detectable torque disturbance thresholds

Considering all three the factors, the minimum detectable torque disturbance for this diagnostic method should be the maximum of these three torque disturbance thresholds. It is quite clear that the torque disturbance threshold from the encoder resolution is the dominant one in this experimental system.

\section{Simulation Studies}

A series of Matlab simulations were applied to verify the assumptions and conversions made for the quantitative theoretical analysis of the disturbance current propagation through the integrated motor drive system shown in Fig.1. Table A of the Appendix shows relevant electrical and mechanical parameters for the experimental system and the system used for the simulation studies. The uncontrolled diode bridge rectifier, PWM inverter and PMSM motor were created with the PLECS toolbox [28].
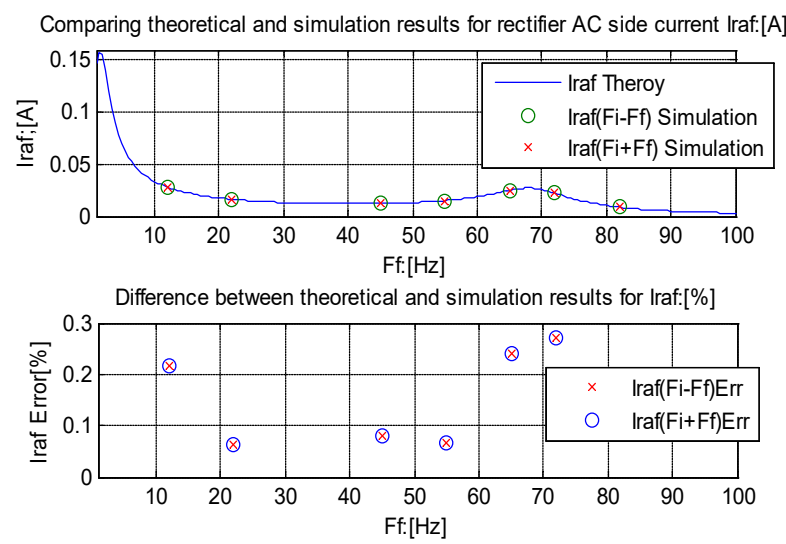

Fig.9 Simulation and theoretical results for the disturbance current in the rectifier input side current and the error between them

The motor speed reference was set to $f_{r}=20 \mathrm{~Hz}$ and the load was approximately $90 \%$ of the rated load which was similar to the load applied in the experimental tests. Different torque disturbance frequencies were applied in the simulation to observe their propagation through the drive. Frequencies considered were $12 \mathrm{~Hz}, 22 \mathrm{~Hz}, 45 \mathrm{~Hz}, 55 \mathrm{~Hz}, 65 \mathrm{~Hz}, 72 \mathrm{~Hz}$ and $82 \mathrm{~Hz}$, and the disturbance torque amplitude was $2 \mathrm{Nm}$. The theoretical results for the rectifier input side disturbance current calculated with (27) are compared with the simulation results and shown in Fig.9. The error for the rectifier input side disturbance current is very tiny. It is clear that the simulation results and the theoretical analysis have a very good agreement. This demonstrates that the theoretical approach employed is valid, particularly the mathematical manipulations and equivalent circuits described in sections III. Ideal components except using a 0.7 volt voltage drop and very small on-resistances $(1 m \Omega)$ for the diodes in the uncontrolled rectifier have been employed as the influence of the non-linearities of the active and passive devices is better illustrated by experiment.

\section{Experimental Results}

This section presents experimental results for the torque signature propagation for the experimental system consisting of a 6-pole $3.82 \mathrm{~kW}$ PM industrial machine and a dc machine as the load. Relevant parameters for the experimental system are given in the Appendix. The bandwidth of the speed loop and current loop are $2.2 \mathrm{~Hz}$ and $433 \mathrm{~Hz}$ respectively. The speed controller is $G_{c s}(s)=(0.47 s+5.1) / s$ and the current controller is designed as $G_{c c}(s)=(21 s+30660) / s$.[20] A PWM inverter using a switching frequency of $10 \mathrm{kHz}$ is implemented. The sampling frequency for the current controllers is $10 \mathrm{kHz}$, while the speed controller is $200 \mathrm{~Hz}$. The PMSM is controlled using indirect vector control by a bespoke DSP based control system. [20] 

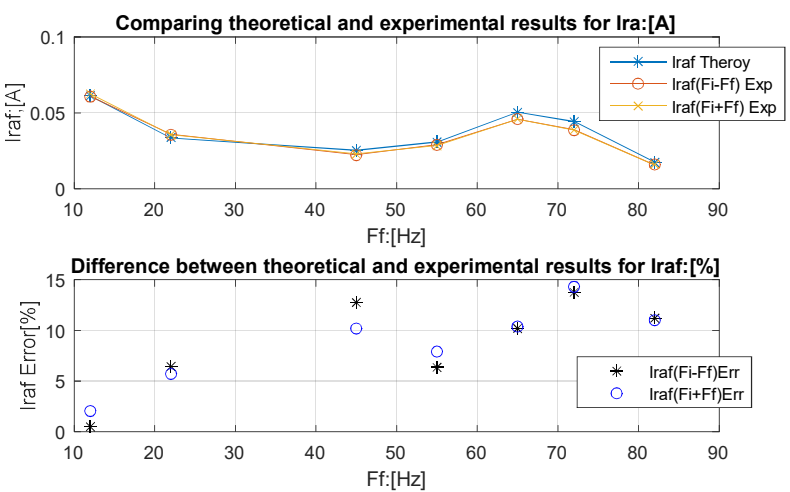

Fig.10 Rectifier ac side fault currents and errors between theoretical and experimental results

To validate the quantitative analysis of the propagation of fault signals, a series of experimental tests were applied, in which a torque disturbance was applied to the PMSM by injecting a specific disturbance current into the armature current of the dc machine to emulate the faulty conditions. The frequency of this injecting current is changed to validate the generalized theoretical analysis. $12 \mathrm{~Hz}, 22 \mathrm{~Hz}$, $45 \mathrm{~Hz}, 55 \mathrm{~Hz}, 65 \mathrm{~Hz}, 72 \mathrm{~Hz}$ and $82 \mathrm{~Hz}$ are randomly selected as example fault frequencies.

The motor was operated at $f_{r}=20 \mathrm{~Hz}$ with approximately $90 \%$ rated load. As the purpose of these tests was to validate the accuracy of the quantitative analysis, $2 \mathrm{Nm}$ torque disturbance is applied to achieve better measurement accuracy. The inverter dc side, rectifier dc side and rectifier ac side currents were measured using an oscilloscope and current probes and analyzed off-line using a MATLAB FFT program [28] to obtain the disturbance current amplitudes.
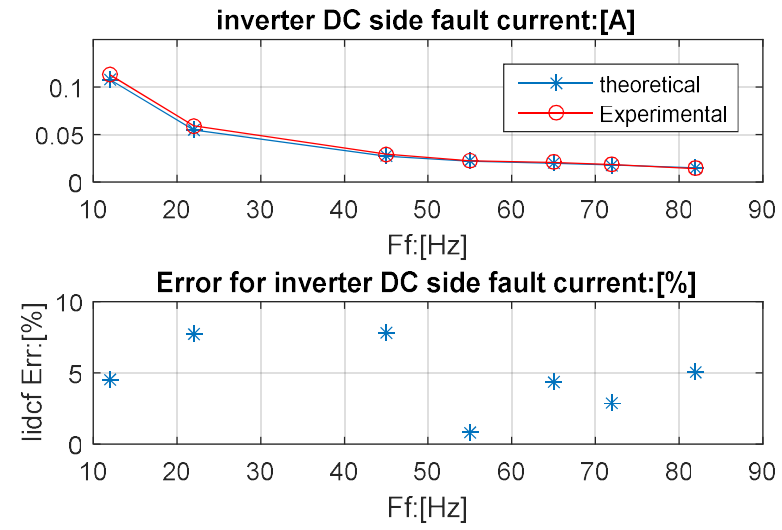

Fig. 11 Inverter dc side fault currents and errors between theoretical and experimental results

In Fig.10, the predicted and measured rectifier ac side disturbance currents are compared, while the predicted and measured inverter dc side disturbance current are illustrated and compared in Fig.11. The theoretical and experimental results match very well (to within $15 \%$ error). This is a reasonable error level for an experimental system, considering that the system contains several non-linearities which have been ignored in the theoretical analysis. Perhaps the dominant assumption is that the dc and ac inductors are considered to be linear (i.e. both saturation and skin depth effects have been ignored).

From the simple experimental tests considered here it can been seen that torque disturbance frequencies in the range $0-100 \mathrm{~Hz}$ can be detected by analyzing the rectifier input current. For the rotational speed used in the tests $(20 \mathrm{~Hz}$ mechanical $)$ the main mechanical fault frequencies that could occur in this range are: $20 \mathrm{~Hz}$ and $40 \mathrm{~Hz}$ due to gearing box faults (gear ratio $=1$ ) or eccentricity faults and $76.8 \mathrm{hz}, 123.2 \mathrm{~Hz}, 35.4 \mathrm{~Hz}$ and $7.68 \mathrm{~Hz}$ caused by the outer race, the inner race, the ball and the cage defect of the bearing respectively (for the 5414 bearing used in the experimental system). Further work is required here to demonstrate that the method can identify specific mechanical faults.

From Fig. 10, the resonant frequency at $68 \mathrm{~Hz}$ can be observed clearly, which is determined by the dc link inductance, capacitance, and rectifier ac side inductance. It can be seen that the disturbance current in the rectifier dc side is amplified several times compared to the disturbance current in the inverter dc side current when the disturbance frequency is close to the resonant frequency. This amplification also affects the magnitude of the disturbance component in the supply current. This means that condition monitoring may be easier for disturbance frequencies around the resonant frequency - something which may be exploited in the final condition monitoring algorithm. A more accurate representation of the passive components (including parasitic resistance) needs to be incorporated in the equivalent circuit if this is to be exploited.

\section{DISCUSSION}

To put the work into context, a real gearbox fault signature has been investigated. A second experimental rig contains a variable speed motor which drives a programmable magnetic brake through a 2 stage planetary gearbox and a parallel shaft gearbox [29]. A fault was introduced by removing a tooth from the second stage of the planetary gear. The mechanical torque measured by the torque transducer is illustrated in Fig 12, when the motor was operating at $20 \mathrm{~Hz}$ and the full load. The resultant torque disturbance appeared at the rotation frequency $\left(f_{r}=20 \mathrm{hz}\right)$, and also $2 f_{r}$, and $3 f_{r}$. The most significant torque disturbance is located at $f_{r}$ whose amplitude is about $6 \%$ of the rated torque. This is approximately one fifth of the size of the disturbance used in section $\mathrm{V}$, and can therefore potentially be detected in the supply side current if sufficient resolution is available in the supply current transducers and data acquisition equipment. The minimum detectable torque disturbance for a specific system will be determined by the bandwidth of the speed and current controllers, the mechanical parameters (inertial and friction), circuit parameters of LC filter, the 
torque disturbance frequency and also the motor current measurement accuracy and the rectifier input current measurement accuracy.

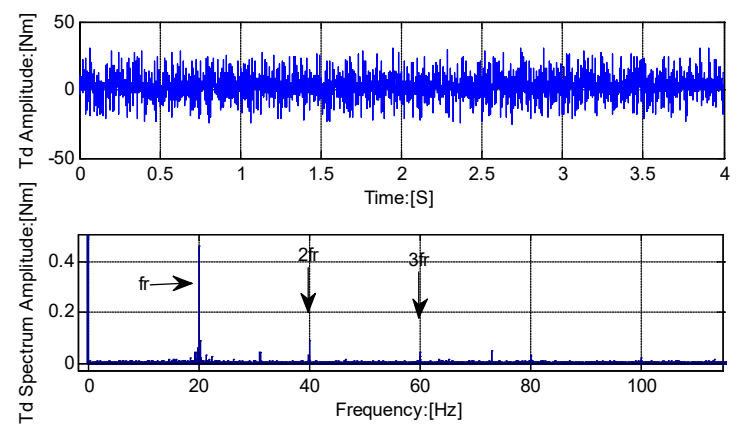

Fig 12. mechanical torque and spectrum with faulty gearbox

It should also be noted that the method is also applicable to drives fed from a dc supply. DCs may be used for future aircraft and marine power distribution systems. Fig. 11 shows that a stronger current signature appears in the inverter dc side current, before being attenuated by the LC components of the dc link filter in the experimental tests address in section VII. The analysis presented in this paper may also be of use in these applications.

\section{Conclusions}

This paper has presented a quantitative theoretical analysis of the fault signal propagation through a permanent magnet synchronous motor drive: from the torque disturbance at the shaft caused by the mechanical faults to the rectifier input currents. The simulation and experiment results verify the good accuracy for using the method to predict the amplitude of the harmonic frequencies in the input related to torque disturbances. The analyses could therefore be used as part of a condition monitoring process. For example it could be used to theoretically set the threshold values for harmonic frequencies measured in the input current, which correspond to the onset of severe mechanical faults which could require the drive to cease operation.

\section{ACKNOWLEDGMENT}

The authors would like to acknowledge the support provided for this work by GE Aviation and EPSRC as part of the SMARTPACT University Technology Strategic Partnership.

\section{APPENDIX}

TABLE A: ELECTRICAL PARAMETERS FOR THE PM MACHINE AND DRIVE CIRCUIT

\begin{tabular}{|c|c|c|c|}
\hline \multicolumn{2}{|c|}{ PM motor } & \multicolumn{2}{c|}{ Drive Circuit } \\
\hline Number of poles: & 6 & dc link & $11.3 \mathrm{mH}$ \\
Rated speed: & $3000(\mathrm{rpm})$ & inductance: $L$ & \\
Rated torque: & $12.2(\mathrm{Nm})$ & dc link & $0.49 \Omega$ \\
\hline
\end{tabular}

\begin{tabular}{|c|c|c|c|}
\hline Rated power: & $3.82(\mathrm{~kW})$ & inductor & \\
Kt: & $1.6(\mathrm{Nm} / \mathrm{A})$ & resistance: $R_{l}$ & $470 \mu F$ \\
Ke: & 98 & dc link & \\
& $\left(\right.$ Vrms $\left./ \mathrm{krpm}^{2}\right)$ & capacitance: $C$ & \multirow{2}{*}{$0.388 \Omega$} \\
Inertia: & $20.5\left(\mathrm{kgcm}^{2}\right)$ & dc link & \\
R (ph-ph): & $0.94 \Omega$ & capacitor & \\
L (ph-ph): & $8.3 \mathrm{mH}$ & resistance $R c$ & \\
\hline
\end{tabular}

\section{REFERENCES}

Periodicals :

[1] V. Climente-Alarcon, J. A. Antonino-Daviu, F. Vedre, x00F, S. $\mathrm{o}$, and R. Puche-Panadero, "Vibration Transient Detection of Broken Rotor Bars by PSH Sidebands," IEEE Transactions on Industry Applications, vol. 49, pp. 2576-2582, 2013.

[2] O. O. Ogidi, P. S. Barendse, and M. A. Khan, "Detection of Static Eccentricities in Axial-Flux Permanent-Magnet Machines With Concentrated Windings Using Vibration Analysis," IEEE Transactions on Industry Applications, vol. 51, pp. 4425-4434, 2015.

[3] L. Frosini, C. Harli, x015F, ca, L. Szab, and x00F, "Induction Machine Bearing Fault Detection by Means of Statistical Processing of the Stray Flux Measurement," IEEE Transactions on Industrial Electronics, vol. 62, pp. 1846-1854, 2015.

[4] J. Hey, A. C. Malloy, R. Martinez-Botas, and M. Lamperth, "Online monitoring of electromagnetic losses in an electric motor indirectly through temperature measurement," IEEE Transactions on Energy Conversion, vol. PP, pp. 1-1, 2016.

[5] A. M. El-Refaie, "Fault-tolerant permanent magnet machines: a review," IET Electric Power Applications, vol. 5, pp. 59-74, 2011.

[7] S. B. Lee, D. Hyun, T. j. Kang, C. Yang, S. Shin, H. Kim, et al., "Identification of False Rotor Fault Indications Produced by Online MCSA for Medium-Voltage Induction Machines," IEEE Transactions on Industry Applications, vol. 52, pp. 729-739, 2016.

[8] J. A. Corral-Hernandez, J. Antonino-Daviu, J. Pons-Llinares, V. Climente-Alarcon, V. Franc, x00E, et al., "Transient-Based Rotor Cage Assessment in Induction Motors Operating With Soft Starters," IEEE Transactions on Industry Applications, vol. 51, pp. 3734-3742, 2015.

[9] S. Cheng and T. G. Habetler, "Using Only the DC Current Information to Detect Stator Turn Faults in Automotive ClawPole Generators," IEEE Transactions on Industrial Electronics, vol. 60, pp. 3462-3471, 2013.

[11] R. M. Tallam, T. G. Habetler, and R. G. Harley, "Transient model for induction machines with stator winding turn faults," IEEE Transactions on Industry Applications, vol. 38, pp. 632-637, 2002.

[12] P. Zhang and P. Neti, "Detection of Gearbox Bearing Defects Using Electrical Signature Analysis for Doubly Fed Wind Generators," IEEE Transactions on Industry Applications, vol. 51, pp. 2195-2200, 2015.

[13] C. P. Mbo'o and K. Hameyer, "Fault diagnosis of bearing damage by means of the linear discriminant analysis of stator current features from the frequency selection," IEEE Transactions on Industry Applications, vol. PP, pp. 1-1, 2016.

[14] G. Xiang and Q. Wei, "Bearing Fault Diagnosis for Direct-Drive Wind Turbines via Current-Demodulated Signals," Industrial Electronics, IEEE Transactions on, vol. 60, pp. 3419-3428, 2013.

[15] B. M. Ebrahimi, J. Faiz, and M. J. Roshtkhari, "Static-, Dynamic, and Mixed-Eccentricity Fault Diagnoses in Permanent-Magnet Synchronous Motors," Industrial Electronics, IEEE Transactions on, vol. 56, pp. 4727-4739, 2009.

[17] S. Shinnaka and Y. Amano, "Elliptical Trajectory-Oriented Vector Control for Energy-Efficient/Wide-Speed-Range Drives of Sensorless PMSM," IEEE Transactions on Industry Applications, vol. 51, pp. 3169-3177, 2015.
P. Kshirsagar, R. P. Burgos, J. Jihoon, A. Lidozzi, W. Fei, D. Boroyevich, et al., "Implementation and Sensorless Vector- 
Control Design and Tuning Strategy for SMPM Machines in Fan-Type Applications," Industry Applications, IEEE Transactions on, vol. 48, pp. 2402-2413, 2012.

[19] P. Zhang, T. G. Habetler, Y. Du, and B. Lu, "A Survey of Condition Monitoring and Protection Methods for MediumVoltage Induction Motors," Industry Applications, IEEE Transactions on, vol. 47, pp. 34-46, 2011.

[21] W. Le Roux, R. G. Harley, and T. G. Habetler, "Detecting faults in rotors of PM drives," Industry Applications Magazine, IEEE, vol. 14, pp. 23-31, 2008.

[24] M. Sakui and H. Fujita, "An analytical method for calculating harmonic currents of a three-phase diode-bridge rectifier with DC filter," Power Electronics, IEEE Transactions on, vol. 9, pp. 631637, 1994.

Books :

[6] L. R. Peter Tavner, Jim Penman,Howard Sedding, Condition Monitoring of Rotating Electrical Machines. London: The Institution of Eingineering and Technology,London,UK, 2008.

[16] V. Wowk., Machinery vibration : measurement and analysis, 1991.

[22] M. H. Rashid, Power electronics : circuits, devices, and applications, 3rd ed., International ed ed., 2004.

[23] J. F. Gieras, Permanent Magnet Motor Technology : Design and Applications: New York : Marcel Dekker, 2002.

[27] T. A. L. D.W. Novotny Vector control and dynamics of AC drives 1996.

[28] V. K. Madisetti, The digital signal processing handbook. Digital signal processing fundamentals, 2nd ed ed. London Boca Raton.Fla.;London:CRC Press, c2010., 2010.

[29] Manual of Drivetrain Diagnostics Simulator by SpectraQuest,Inc., 2010.

Papers from Conference Proceedings (Published):

[10] J. Arellano-Padilla, M. Sumner, C. Gerada, and J. Li, "A novel approach to gearbox condition monitoring by using drive rectifier input currents," in Power Electronics and Applications, 2009. EPE '09. 13th European Conference on, 2009, pp. 1-10.

[20] J. Li, M. Sumner, J. Arellano-Padilla, and G. Asher, "Condition monitoring for mechanical faults in motor drive systems using the recifier input currents," in Power Electronics, Machines and Drives (PEMD 2010), 5th IET International Conference on, 2010, pp. 1-6.

[25] K. N. Areerak, S. V. Bozhko, G. M. Asher, and D. W. P. Thomas, "DQ-transformation approach for modelling and stability analysis of AC-DC power system with controlled PWM rectifier and constant power loads," in Power Electronics and Motion Control Conference, 2008. EPE-PEMC 2008. 13th, 2008, pp. 2049-2054.

[26] L. Jing, M. Sumner, J. Arellano-Padilla, and G. Asher, "Operating limits for drive condition monitoring using supply current signature analysis," in Electric Machines \& Drives Conference (IEMDC), 2011 IEEE International, 2011, pp. 412417. 